\title{
O impacto da judicialização no Brasil em relação à cirurgia do implante coclear no Sistema Único de Saúde
}

\section{RESUMO}

Objetivo:descrever o impacto da Judicialização na realização da cirurgia de Implante Coclear (IC) no Sistema Único de Saúde do Brasil (SUS), incluindo o serviço público e a saúde suplementar. Metodologia: foi realizado um levantamento de acórdãos de todos os Tribunais Nacionais e a Jurisprudência Dominante voltados à cirurgia do IC no SUS no período de 2007 a 2019 por meio da Plataforma Jusbrasil. Resultados: foram encontrados um total de 995 processos relacionados ao IC. Destes, 265 processos foram trazidos em duplicidade pela Plataforma Jusbrasil e 283 processos tratavam-se de solicitações genéricas requeridas pelo usuário de IC, como por exemplo, aposentadoria por invalidez, concessão de benefícios, acidente de trabalho, dentre outros.Desta forma, 447 processos estavam voltados à reabilitação, sendo que 231 processos contemplavam a manutenção do IC e 216 a solicitação da cirurgia do IC, unilateral ou bilateral. Ao considerar que o enfoque do presente estudo está na cirurgia do IC, unilateral ou bilateral, os dados se referem a um total de 216 processos. Inicialmente, constatou-se que 166 (76,8\%) eram solicitações para o IC unilateral e $50(23,1 \%)$ para IC bilateral. A judicialização foi observada nos Estados mais ricos e o sistema jurídico tem demonstrado coerência em suas decisões, visto que a Tutela Antecipada foi confirmada com a decisão final favorável em todos os casos em que o cidadão, por meio de documentos, demonstrou a necessidade e urgência do procedimento. Conclusão: mesmo após a regulamentação do Ministério da Saúde no ano de 1999 para IC unilateral e no ano de 2014 para IC bilateral, e pela ANS no ano de 2012 para IC unilateral e bilateral a Judicialização está presente para que o cidadão que busca assistência à saúde, menor de idade e adulto, tenha acesso ao seu direito constitucionalmente garantido.

Palavras-chave: Implante Coclear. Direitos Civis. Direito à Saúde. Política Pública. Judicialização da Saúde. 